\title{
A PROPOSED JOURNAL OF APPLIED MATHEMATICS
}

During the past two years a school for advanced instruction in applied mechanics has been conducted at Brown University with notable success. One result has been to form a group of men from many different centers who desire to make a permanent place for advanced applied mathematics in this country. To this end, it has now been decided to publish a Journal of Applied Mathematics, to appear quarterly, and to form a volume of $300-400$ pages annually. The first issue will be as for January, 1943, although actual publication may be delayed beyond that month.

From time to time over the past two decades, a journal of this type has been proposed, but the project has never been brought to a focus. This journal, as now planned, is to fill the gap between purely engineering journals and purely mathematical ones. It will provide a place where the various subjects can be regarded as sciences, and where any piece of work which fills a gap in this structure or extends it, can be accepted without having to show immediate application to engineers or fundamentally new ideas of mathematical interest to mathematicians.

Not only must applied mathematics serve the war effort, as it is now doing in increasing measure, but, looking ahead to the postwar period, it appears essential that America should be strong in the whole field of Science in order that it serve as a world center for advanced instruction and research. The new journal will aid in bringing America to the forefront in applied mechanics and in other branches of applied mathematics. It is hoped that many mathematicians will approve and will give this project both moral and financial support.

The Board of Editors will be:

Dr. H. L. Dryden, Physicist, National Bureau of Standards.

Dr. T. C. Fry, Mathematical Research Director, Bell Telephone Laboratories.

Dr. W. Prager, Professor of Applied Mathematics, Brown Univ.

Dr. I. S. Sokolnikoff, Professor of Mathematics, Univ. of Wisconsin.

Dr. J. L. Synge, Professor of Applied Mathematics, Univ. of Toronto.

Dr. Th. von Kármán, Professor of Aeronautical Engineering, Calif. Inst. of Tech.; Consultant, Northrop Aircraft, Inc.

These names will carry a message of confidence of high standards to all who know the field. Some fifteen others, eminent in their fields, will be asked to accept appointments as collaborators.

E. R. HEDRICK 